\title{
AN INVESTIGATION ON IN VITRO AND IN VIVO ANTIMICROBIAL PROPERTIES OF THE ANTIDEPRESSANT: AMITRIPTYLINE HYDROCHLORIDE
}

\author{
Anurup Mandal, Chandrima Sinha, Aditya Kumar Jena, Soma Ghosh, Amalesh Samanta*
}

Division of Microbiology, Department of Pharmaceutical Technology, Jadavpur University, Kolkata (Calcutta)-700032, India.

Submitted: August 28, 2009; Returned to authors for corrections: March 19, 2010; Approved: April 26, 2010.

\begin{abstract}
The antidepressant drug amitriptyline hydrochloride was obtained in a dry powder form and was screened against 253 strains of bacteria which included 72 Gram positive and 181 Gram negative bacteria and against 5 fungal strains. The minimum inhibitory concentration (MIC) was determined by inoculating a loopful of an overnight peptone water culture of the organism on nutrient agar plates containing increasing concentrations of amitriptyline hydrochloride $(0,10 \mu \mathrm{g} / \mathrm{mL}, 25 \mu \mathrm{g} / \mathrm{mL}, 50 \mu \mathrm{g} / \mathrm{mL}, 100 \mu \mathrm{g} / \mathrm{mL}, 200$ $\mu \mathrm{g} / \mathrm{mL}$ ). Amitriptyline hydrochloride exhibited significant action against both Gram positive and Gram negative bacteria at $25-200 \mu \mathrm{g} / \mathrm{mL}$. In the in vivo studies it was seen that amitriptyline hydrochloride at a concentration of $25 \mu \mathrm{g} / \mathrm{g}$ and $30 \mu \mathrm{g} / \mathrm{g}$ body weight of mouse offered significant protection to Swiss strain of white mice when challenged with 50 median lethal dose (MLD) of a virulent strain of Salmonella typhimurium NCTC 74 . The in vivo data were highly significant $(\mathrm{p}<0.001)$ according to the chi-square test.
\end{abstract}

Key words: Amitriptyline hydrochloride, antimicrobial activity, non antibiotics.

\section{INTRODUCTION}

The history of development of pharmacological compounds has shown that any agent may possess diverse functions and may therefore have useful activity in the completely different field of medicine. The possible multifunctional nature of most medicinal agents prompted scientists to investigate the antimicrobial properties of compounds classified pharmacologically as psychotropics, tranquilizers, local anesthetics, cardiovascular drugs, antiinflammatory agents and antihistamines. It was found that chlorpromazine $(14,19)$, promazine (6), trifluoperazine (16), fluphenazine (7), bromodiphenhydramine $(12,23)$, tripolidine
(22), methdilazine (4), promethazine (3), trimeprazine (10), propranolol (15), methyl DOPA (11), nifedipine (21), amlodipine (2), dobutamine (24), lacidipine (5), procaine and lignocaine (8), diclofenac $(1,9)$, dicyclomine (13) possess significant antimicrobial activity.

From these studies it was observed that the compounds with two or more benzene rings possess powerful antimicrobial activity. The present paper describes a detailed study on the in vitro and in vivo antimicrobial activity of a tricyclic antidepressant drug: amitriptyline hydrochloride in which two benzene rings are attached to one another by a cycloheptene ring. 


\section{MATERIALS AND METHODS}

\section{Microorganisms}

A total of 253 strains of bacteria from 5 Gram positive and 11 Gram negative genera and 5 fungal strains belonging to 3 genera were used in this study.

Different bacterial and fungal strains used were isolated from patients or obtained from collections at different places. From Kolkata- Gram positive Staphylococcus aureus (ATCC 6538 p, ATCC 25923, ATCC 29737, BDC 1, ML 6, ML 14, ML 17, ML36, ML 37, ML 52, ML 58, ML 81, ML 125, ML 145, ML 149, ML 151, ML 152,ML 159, ML 162, ML174, ML 180, ML 198, ML 264, ML 265,ML 267, ML 269, ML 271, ML 275, ML 276, ML 277, ML 295, ML 311, ML 314, ML 321, ML 322, ML 329, ML 330, ML 333, ML 335, ML 345, ML 351, ML 358, ML 384, ML 394, ML 411, ML 420, ML 422, Bang 44, 3, 15, 17, 40), Staphylococcus saprophyticus VS14, Staphylococcus citreus $\mathrm{M}_{1}$, Staphylococcus lactis 309, Streptococcus faecalis (ATCC 29212, S2), Micrococcus luteus (ATCC 9341, AGD1), Bacillus cereus ATCC 11778 and Lactobacillus sporogenus; Gram negative Shigella flexneri (2a NK 307, 2a 33220, 3a 30903, 5a B 18603, 5a BCH 511, 2b DN 13, 3b NK 331, 6 NK 126, 6 BCH 895, 6 BCH 999, 6E 03429, F20520, F 20570, BDC 1), Shigella sonnei (B 22461, BCH 217, BCH 397, BCH 947, DN 3, DN 9, E 08869, F11001, KS 1, NK 2, NK 29, NK 228, NK840), Shigella boydii 9E16552, Salmonella virchow ATCC3.1, Salmonella derby ATCC 3.2, Salmonella senftenberg ATCC3.4, Salmonella F14669, Vibrio cholerae (ATCC14033,10, 39, 56, 69, 71, 117, 133, 142, 154, 156, Kathmandu 2, 289, 411, 547, 553, 730, 752, 792, 793, $805,810,811,813,820,834,852,865,941,955,1021,1023$, 1311, 1315, 1342, 1351, 229, Kualalumpur 23, Kualalumpur 37, DN 6, DN 7, DN 16, DN 26, VRC 411, VRC 2080, VRC 423/75, VRC 2002/75, VRC 2004/75, VRC 295/76, VRC 369/76, DN 6, DN 7, DN 16, DN 26), Escherichia coli (ATCC 10536, ATCC 25922, ATCC 25938, 721, 809, 54B, UC 51, 3P/SD, R 224, R 239, 870, 55, 319, TG1, NCTC 10 HD, 424, 868, 871, C1, R122), Klebsiella pneumoniae (1, 725, J14, J/1/4, R114, R119), Pseudomonas aeruginosa (ATCC 25619,
ATCC 27853, AMRI 100), Proteus mirabilis (10, 21, 32, C/6/5, C/10/6), Proteus vulgaris SSKM1/01, Providencia spp., Hafnia spp., Enterobacter cloacae and Citrobacter spp. and fungal strains Candida albicans (I, II, ATCC 10231), Cryptococcus spp. and Rhodotorula spp., from New Delhi Gram negative Pseudomonas aeruginosa (7, 71, 732, 1006, APC1, C/1/5, C/1/7, Kr/12/3), from London - Gram positive Staphylococcus aureus (NCTC 8530, NCTC 8531, NCTC 8532, NCTC 6571), Bacillus brevis NCTC 7096, Bacillus polymyxa NCTC 4747, Bacillus pumilus NCTC 8241, Bacillus licheniformis NCTC 10341 and Bacillus subtilis ATCC 6633; Gram negative Shigella dysenteriae (2 NCTC 566/61, 7 NCTC 519/66, 8 NCTC 599/52, 9 NCTC 7919), Shigella flexneri 1B 67800, Shigella boydii 10 NCTC 386/66, Salmonella typhi (NCTC 59 type2, NCTC 62), Salmonella berta 69, Salmonella choleraesuis 36, Salmonella paratyphi (A 2, B 5), Salmonella viballerup and Salmonella typhimurium (NCTC 11, NCTC 74, NCTC 102), from U.K. - Gram negative Shigella sonnei $(2,17)$ and Escherichia coli K12 ROW, from Japan - Gram negative Vibrio parahaemotlyticus (732, 734, 916, 4750, 5507, 8742, 8848, 8898, 8942, 9166, 9331, 9369, 9379, 9580, 9601, 9602, 9603, 9606, 9701, 72003, 72006, 72008, 72016, 72040, 72172, P1, P3, P4, P5, P7), from Denmark - Gram negative Escherichia coli K 99 and from USA- Gram positive Staphylococcus aureus UT 0002 and Bacillus subtilis UC 564; Gram negative Escherichia coli V 517 and Pseudomonas Putida 61 were collected.

All the strains are maintained in the Division of Microbiology, Department of Pharmaceutical Technology, Jadavpur University, Kolkata.

\section{Drug}

The drug amitriptyline hydrochloride was obtained in pure dry powder form, from Sun Pharmaceuticals Laboratories, Dadra, India.

\section{In vitro screening test against bacteria}

The bacteria were grown in peptone water (PW, $1.0 \%$ bacteriological peptone, Difco brand, 0.5\% Analar $\mathrm{NaCl}$ ) 
for $18 \mathrm{~h}$. An aqueous solution of amitriptyline hydrochloride $(1 \mathrm{mg} / \mathrm{mL})$ was sterilized by filtration (sintered glass filter, G-5) and stored at $4^{\circ} \mathrm{C}$. This was added to molten nutrient agar (Difco brand) at $45^{\circ} \mathrm{C}$ in varied final concentrations: 0 (control), $10,25,50,100,200 \mu \mathrm{g}$ per $\mathrm{mL}$ of nutrient agar. The final $\mathrm{pH}$ of all the media were adjusted to 7.2 to 7.4 before pouring into sterile Petri dishes. The minimum inhibitory concentration (MIC) of amitriptyline hydrochloride was determined by spotting one loopful (internal diameter $2 \mathrm{~mm}$ ) of a diluted $18 \mathrm{~h}$ broth containing $5 \times 10^{5}$ colony forming units (CFU) on all plates which were incubated at $37^{\circ} \mathrm{C}$ and examined for growth up to $72 \mathrm{~h}$ (20). The test was performed in triplicate for each organism and the experiment was repeated when necessary.

\section{In vitro screening test against fungi}

The fungal strains were grown in Sabouraud's glucose broth (Difco brand). The sterile aqueous amitriptyline hydrochloride solution (1 $\mathrm{mg} / \mathrm{mL})$ was added to molten Sabouraud's glucose agar (SGA) in such concentrations that the final concentrations of amitriptyline hydrochloride were 0 $\mu \mathrm{g} / \mathrm{mL}$ (control), $100 \mu \mathrm{g} / \mathrm{mL}, 200 \mu \mathrm{g} / \mathrm{mL}, 500 \mu \mathrm{g} / \mathrm{mL}, 1000$ $\mu \mathrm{g} / \mathrm{mL}$. The final $\mathrm{pH}$ of SGA media were adjusted to 5.4 before preparing slants in sterile test tubes. The broth of the fungal strain was diluted and adjusted to $0.5 \mathrm{McF}$ arland standard (17) (a turbidity standard prepared by adding $0.5 \mathrm{~mL}$ of $1 \%$ barium chloride solution to $99.5 \mathrm{~mL}$ of $1 \% \mathrm{H}_{2} \mathrm{SO}_{4}$ ) and then the slant tubes were inoculated with one loopful (internal diameter $2 \mathrm{~mm}$ ) of this diluted broth, and the tubes were then incubated at $28^{\circ} \mathrm{C}$ for 7 days. The end points were noted, when growth of colonies of control were clearly visible after incubation for 7 days (25).

\section{Determination of antibacterial activity of amitriptyline hydrochloride}

Two milliliters of $18 \mathrm{~h}$ broth culture of a bacterium sensitive to amitriptyline hydrochloride were added to $4 \mathrm{~mL}$ of fresh nutrient broth (NB) and were incubated at $37^{\circ} \mathrm{C}$ for $2 \mathrm{~h}$, to reach the logarithmic growth phase. The number of viable organisms (CFU/mL) was determined and amitriptyline hydrochloride was added at this point at a concentration twice of the respective MIC value. The $\mathrm{CFU} / \mathrm{mL}$ counts were determined up to $6 \mathrm{~h}$ at $2 \mathrm{~h}$ interval and then after $18 \mathrm{~h}$.

\section{Animal protection test}

In vivo experiments were conducted on 50-60 days old male Swiss albino mice weighing $18-20 \mathrm{~g}$. They were kept in polypropylene cages containing 5 animals per cage. Mortality experiment with or without amitriptyline hydrochloride were carried out by challenging mice with 50 median lethal dose (MLD) of a passaged virulent strain of Salmonella typhimurium NCTC 74 (corresponding to $0.95 \times 10^{9}$ C.F.U. suspended in $0.5 \mathrm{~mL} \mathrm{NB}$ ) (7). Reproducibility of the challenge test doses was ensured by standardization of its optical density at $640 \mathrm{~nm}$ in a Klett Summerson colorimeter to give the predetermined number of $\mathrm{CFU}$ per $\mathrm{mL}$ of broth on nutrient agar plates. The MIC of amitriptyline hydrochloride against $S$. typhimurium NCTC 74 was found to be $200 \mu \mathrm{g} / \mathrm{mL}$. Three hours before the challenge, amitriptyline hydrochloride was intraperitoneally administered to the animals in doses of 2, 3, $4.5,6,10,20,25,30 \mu \mathrm{g}$ per $\mathrm{g}$ body weight of mice in a final volume of $0.1 \mathrm{~mL}$. The control group was injected with $0.1 \mathrm{~mL}$ of sterile water, and all the animals were observed up to $100 \mathrm{~h}$. As survival rate is very low for control group, 60 animals were taken in that group for getting statistically significant data.

In a similar experiment 10 mice were divided into 2 groups of 5 each, and all of them were injected with the challenge dose; Group I was given amitriptyline hydrochloride (25 $\mu \mathrm{g} / \mathrm{g}$ of mouse) while Group II was given sterile water before the challenge.

All the animals of Group I and Group II were anesthetized by diethyl ether and then were autopsied $18 \mathrm{~h}$ after the challenge. Their livers and spleens were removed, homogenized in a sterile glass homogenizer and preserved at $20^{\circ} \mathrm{C}$ for subsequent determination of viable counts (C.F.U./mL); $0.2 \mathrm{~mL}$ to $0.4 \mathrm{~mL}$ of heart blood was also collected aseptically at the same time and viable count was determined immediately.

Animal experiments were conducted following the guidelines of the Institutional Animal Ethics Committee. 


\section{RESULTS}

\section{Determination of antibacterial activity of amitriptyline} hydrochloride by in vitro test

Amitriptyline hydrochloride was found to possess significant antibacterial activity against both Gram positive and Gram negative bacteria. From Table 1, it was seen that out of 253 strains of bacteria tested, 28 strains $(11 \%)$ were inhibited at $25 \mu \mathrm{g} / \mathrm{mL}, 16$ strains $(6 \%)$ were inhibited at $50 \mu \mathrm{g} / \mathrm{mL}, 55$ strains $(22 \%)$ were inhibited at $100 \mu \mathrm{g} / \mathrm{mL}$ and 86 strains
(34\%) were inhibited at $200 \mu \mathrm{g} / \mathrm{mL}$ of amitriptyline hydrochloride. The drug has significant inhibitory action on Staphylococcus spp., Bacillus spp. and Vibrio cholerae; 39 out of 60 strains $(65 \%)$ of Staphylococcus spp., 6 out of 7 strains (86\%) of Bacillus spp. and 31 out of 50 strains (62\%) of Vibrio cholerae were inhibited at $25-100 \mu \mathrm{g} / \mathrm{mL}$ concentration of amitriptyline hydrochloride. Bacillus was the most sensitive amongst all Gram positive organisms tested. The drug has moderate inhibitory action on Shigella, Salmonella, $V$. parahaemolyticus and E. coli.

Table 1. In vitro activity of amitriptyline hydrochloride on Gram positive and Gram negative bacteria

\begin{tabular}{|c|c|c|c|c|c|c|c|}
\hline \multirow[t]{2}{*}{ Name of bacteria } & \multirow{2}{*}{$\begin{array}{c}\text { No. of strains } \\
\text { tested }\end{array}$} & \multicolumn{6}{|c|}{ No. of strains inhibited by amitriptyline hydrochloride $(\mu \mathrm{g} / \mathrm{mL})$} \\
\hline & & 10 & 25 & 50 & 100 & 200 & $>200$ \\
\hline Staphylococcus spp. & 60 & & $9(15 \%)$ & $2(3 \%)$ & $28(47 \%)$ & $16(27 \%)$ & $5(8 \%)$ \\
\hline Streptococcus faecalis & 2 & & & & & & $2(100 \%)$ \\
\hline Micrococcus luteus & 2 & & $1(50 \%)$ & & & $1(50 \%)$ & \\
\hline Bacillus spp. & 7 & & $5(72 \%)$ & & $1(14 \%)$ & & $1(14 \%)$ \\
\hline Shigella spp. & 36 & & $1(3 \%)$ & $4(11 \%)$ & $2(6 \%)$ & $18(50 \%)$ & $11(30 \%)$ \\
\hline Salmonella spp. & 14 & & $2(14 \%)$ & $1(7 \%)$ & $2(14 \%)$ & $4(29 \%)$ & $5(36 \%)$ \\
\hline Vibrio cholerae & 50 & & $7(14 \%)$ & $9(18 \%)$ & $15(30 \%)$ & $16(32 \%)$ & $3(6 \%)$ \\
\hline Vibrio parahaemolyticus & 30 & & & & $2(7 \%)$ & $22(73 \%)$ & $6(20 \%)$ \\
\hline Escherichia coli & 23 & & & & $4(17 \%)$ & $8(35 \%)$ & $11(48 \%)$ \\
\hline Klebsiella pneumoniae & 6 & & & & & $1(17 \%)$ & $5(83 \%)$ \\
\hline Pseudomonas spp. & 12 & & $1(8 \%)$ & & $1(8 \%)$ & & $10(84 \%)$ \\
\hline Proteus spp. & 6 & & & & & & $6(100 \%)$ \\
\hline Citrobacter spp. & 1 & & $1(100 \%)$ & & & & \\
\hline Providencia spp. & 1 & & & & & & $1(100 \%)$ \\
\hline Enterobacter cloacae & 1 & & & & & & $1(100 \%)$ \\
\hline Hafnia spp. & 1 & & & & & & $1(100 \%)$ \\
\hline Lactobacillus sporogenes & 1 & & $1(100 \%)$ & & & & \\
\hline Total & 253 & & $28(11 \%)$ & $16(6 \%)$ & $55(22 \%)$ & $86(34 \%)$ & $68(27 \%)$ \\
\hline
\end{tabular}

The MIC of amitriptyline hydrochloride against a representative Staphylococcus aureus NCTC 6571 was found to be $100 \mu \mathrm{g} / \mathrm{mL}$. $200 \mu \mathrm{g} / \mathrm{mL}$ of the drug was added to the $\mathrm{NB}$ culture of S. aureus NCTC 6571 at zero hour of the logarithmic growth phase, when CFU/mL count was $4.4 \times 10^{7}$. After $2 \mathrm{~h}, 4$ $\mathrm{h}, 6 \mathrm{~h}$ the $\mathrm{CFU} / \mathrm{mL}$ count was $4.4 \times 10^{5}, 3.9 \times 10^{5}$ and $3.9 \times 10^{5}$ respectively and at the end of the $18 \mathrm{~h}$ was $3.5 \times 10^{4}$, thereby proving the bacteriostatic nature of amitriptyline hydrochloride against Gram-positive S. aureus NCTC 6571 (Fig. 1).

Similarly as the MIC of amitriptyline hydrochloride against a representative Shigella boydii 10 NCTC 386/66 was $25 \mu \mathrm{g} / \mathrm{mL}, 50 \mu \mathrm{g} / \mathrm{mL}$ of the drug was added at the logarithmic 
growth phase of this culture. The CFU/mL before addition of the drug was $4 \times 10^{7}$ and it was $9 \times 10^{3}$ after $2 \mathrm{~h}, 8.9 \times 10^{3}$ after $4 \mathrm{~h}$ and $8.8 \times 10^{3}$ after $6 \mathrm{~h}$ which did not change further and remained constant at $8.8 \times 10^{3}$ at the end of the $18 \mathrm{~h}$. So the amitriptyline hydrochloride is also bacteriostatic against Gram negative Shigella boydii 10 NCTC 386/66 (Fig. 1).

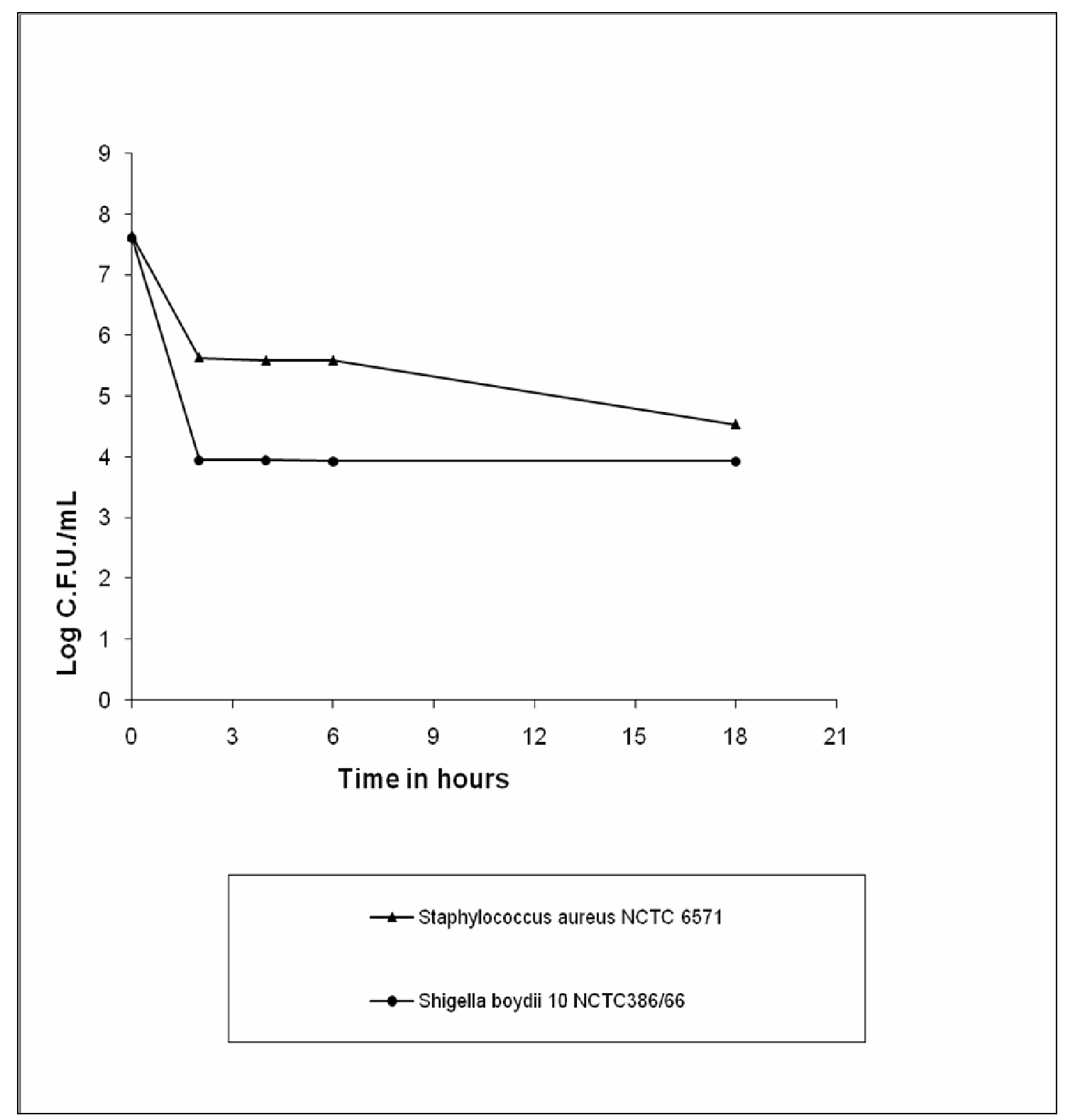

Figure 1. Mode of action of amitriptyline hydrochloride on Staphylococcus aureus NCTC 6571 and Shigella boydii 10 NCTC $386 / 66$

Determination of antifungal activity of amitriptyline hydrochloride by in vitro tests

Table 2 shows that Cryptococcus spp. was inhibited at 500 $\mu \mathrm{g} / \mathrm{mL}$ of amitriptyline hydrochloride. At $1000 \mu \mathrm{g} / \mathrm{mL}$ concentration of the drug the growth of Candida albicans ATCC 10231 and Candida albicans II was reduced indicating the toxigenic effect of amitriptyline hydrochloride against these two strains. 
Table 2. Inhibitory effect of amitriptyline hydrochloride on different fungal strains

\begin{tabular}{|c|c|c|c|c|c|}
\hline \multirow[t]{2}{*}{ Name of fungal strain } & \multicolumn{5}{|c|}{$\begin{array}{l}\text { Growth in SGA containing different concentrations of } \\
\text { amitriptyline hydrochloride }(\mu \mathrm{g} / \mathrm{mL})\end{array}$} \\
\hline & 0* & 100 & 200 & 500 & 1000 \\
\hline Candida albicans ATCC 10231 & + & + & + & + & \pm \\
\hline Candida albicans I & + & + & + & + & + \\
\hline Candida albicans II & + & + & + & + & \pm \\
\hline Rhodotorula spp. & + & + & + & + & + \\
\hline Cryptococcus spp. & + & + & + & - & - \\
\hline
\end{tabular}

\section{In vivo experiments}

The results presented in Table 3 show that in doses of 30 $\mu \mathrm{g} / \mathrm{g}$ and $25 \mu \mathrm{g} / \mathrm{g}$ body weight of mice, only 4 out of 20 mice died in each case, whereas in the control group which received only the drug, no mouse expired. In the control series which received the challenge only, 48 out of 60 mice died. The protection test turned out to be statistically significant $(\mathrm{p}<0.001$ in $\mathrm{x}^{2}$ test) at both $30 \mu \mathrm{g} / \mathrm{g}$ and $25 \mu \mathrm{g} / \mathrm{g}$ doses of amitriptyline hydrochloride, compared to the control (without drug).

Amitriptyline hydrochloride at doses of $25 \mu \mathrm{g} / \mathrm{g}$ body weight of mice significantly reduced the bacterial count $(\mathrm{CFU} / \mathrm{mL})$ in the organ homogenates of mice $18 \mathrm{~h}$ after the challenge compared with the control $(\mathrm{p}<0.01)$. The bacterial count in heart blood was also significantly reduced in treated animals (Table 4).

Table 3. Effect of amitriptyline hydrochloride on survival of mice challenged with Salmonella typhimurium NCTC 74

\begin{tabular}{ccc}
\hline Group & $\begin{array}{c}\text { Dose of Amitriptyline } \\
\text { hydrochloride }(\boldsymbol{\mu g} / \mathbf{g} \text { mice })\end{array}$ & $\begin{array}{c}\text { Survival } \\
\text { (live / total })\end{array}$ \\
\hline Test & 25 & $16 / 20^{*}$ \\
(Challenged) & 30 & $16 / 20^{*}$ \\
\hline Control & - & $12 / 60$ \\
(Challenged) & $(0.1 \mathrm{~mL}$ of Sterile water $)$ & \\
\hline$* \mathrm{P}<0.001$ according to chi-square test, after elimination of the toxic effects due to the drug alone (test-control). The challenge dose
\end{tabular}
was $0.95 \times 10^{9}$ C.F.U. in $0.5 \mathrm{~mL}$ nutrient broth and the survival was recorded up to $100 \mathrm{~h}$ after the administration of drug

Table 4. Efficacy of amitriptyline hydrochloride in reducing bacterial counts in different organs of mice challenged with Salmonella typhimurium NCTC 74 for 18 hours

\begin{tabular}{ccccc}
\hline \multirow{2}{*}{ Group } & Drug/g mouse & \multicolumn{3}{c}{ C.F.U./mL counts in } \\
\cline { 3 - 5 } & & Heart blood & Liver & Spleen \\
\hline I & Amitriptyline hydrochloride $25 \mu \mathrm{g}$ & $5.5 \times 10^{3}$ & $8.5 \times 10^{3}$ & $6.4 \times 10^{3}$ \\
& & to & to & to \\
& & $8.0 \times 10^{4}$ & $9.2 \times 10^{4}$ & $5.8 \times 10^{5}$ \\
\hline II & Sterile water (control) & $4.9 \times 10^{7}$ & $6.2 \times 10^{7}$ & $2.4 \times 10^{7}$ \\
& & to & to & to \\
& & $3.8 \times 10^{8}$ & $2.4 \times 10^{8}$ & $4.6 \times 10^{8}$ \\
\hline
\end{tabular}

After drug administration, the animals ( 5 mice per group) were challenged with $0.95 \times 10^{9}$ C.F.U./mL of Salmonella typhimurium NCTC 74 and sacrificed $18 \mathrm{~h}$ later. Their livers and spleen were removed aseptically and the homogenates were prepared for viable counts. The data were analyzed using Student's ' $\mathrm{t}$ ' test and was found to be significant; $\mathrm{p}<0.01$ in $18 \mathrm{~h}$ samples. 


\section{DISCUSSION}

Amitriptyline hydrochloride, a tricyclic antidepressant drug, has been seen to possess powerful antimicrobial activity both in vitro and in vivo experiments. The sensitive bacterial strains occurred among Staphylococcus spp., Bacillus spp., Vibrio cholerae, Micrococcus spp, Lactobacillus sporogenes and Citrobacter spp. The drug was only moderately active with respect to strains of Shigella spp., Salmonella spp., E. coli, Klebsiella pneumoniae, Vibrio parahaemolyticus and Pseudomonas spp. whereas Streptococcus faecalis, Proteus spp., Enterobacter cloacae, Hafnia spp. and Providencia spp. were resistant to Amitriptyline hydrochloride. Amitriptyline hydrochloride also possesses good antifungal activity against Cryptococcus spp. It possesses moderate antifungal activity against Candida albicans but Rhodotorula spp was resistant to the drug. The drug was found to be bacteriostatic in vitro both against Gram positive and Gram negative bacteria.

In our in vivo experiments we found that amitriptyline hydrochloride at $25 \mu \mathrm{g} / \mathrm{g}$ and $30 \mu \mathrm{g} / \mathrm{g}$ body weights significantly protected the mice. Amitriptyline hydrochloride at doses of $25 \mu \mathrm{g} / \mathrm{g}$ body weight of mice significantly reduced the bacterial count $(\mathrm{CFU} / \mathrm{mL})$ in the organ homogenates and heart blood of mice. The high doses required to protect the animals against the challenge of Salmonella typhimurium NCTC 74 may be due to the high in vitro MIC value of amitriptyline hydrochloride against this strain $(200 \mu \mathrm{g} / \mathrm{mL})$. At these doses (25 $\mu \mathrm{g} / \mathrm{g}$ and $30 \mu \mathrm{g} / \mathrm{g}$ ) the drug showed no toxicity and they were very much below the medial lethal dose of amitriptyline hydrochloride in mice (oral) $350 \mu \mathrm{g} / \mathrm{g}$ (18).

The tricyclic phenothiazines in general possess moderate to powerful antimicrobial activities. The antimicrobial activity of methdilazine (4), trimeprazine (10), fluphenazine (7), trifluoperazine (16) have been reported. Investigations on the structure activity relationship (SAR) suggested that the arrangement of the benzene rings may be responsible for the antimicrobial activity of the drug. Amitriptyline hydrochloride containing two benzene rings attached to one another by a cycloheptene ring may be conceived to mimic a phenothiazine structure, thereby explaining its antimicrobial property. The spectrum of action of amitriptyline hydrochloride is similar to other compounds containing two or more benzene ring $(6,7)$.

The in vitro and in vivo studies involving amitriptyline hydrochloride suggest that this drug has a remarkable potential for being developed into a potent antimicrobial agent. Further enhancement of its antimicrobial properties can be achieved by synthesizing derivatives of this drug with appropriate structural modifications.

\section{ACKNOWLEDGEMENT}

The study was supported financially by Dr. V. Ravichandran Endowment Trust, Jadavpur University, Kolkata (Calcutta), India.

\section{REFERENCES}

1. Annadurai, S.; Basu, S.; Ray, S.; Dastidar, S.G.; Chakrabarty, A.N. (1998). Antibacterial activity of the anti-inflammatory agent diclofenac sodium. Indian J. Exp. Biol. 36, 86-90.

2. Asok Kumar, K.; Ganguly, K.; Mazumdar, K.; Dutta, N.K.; Dastidar, S.G.; Chakrabarty, A.N. (2003). Amlodipine: a cardiovascular drug with powerful antimicrobial property. Acta Microbiologica Polonica. 52 (3), 285-292.

3. Chakrabarty, A.N.; Acharya, D.P.; Niyogi, D; Dastidar, S.G. (1989). Drug interaction of some non conventional antimicrobial chemotherapeutic agents with special reference to promethazine. Indian J. Med. Res. 89, 233-237

4. Chattopadhyay, D.; Dastidar, S.G.; Chakrabarty, A.N. (1988). Antimicrobial properties of methdilazine and its synergism with antibiotics and some chemotherapeutic agents. Arzneimittel-Forschung. $38,869-872$.

5. Dasgupta, A.; Jeyaseeli, L.; Dutta, N.K.; Mazumder, K.; Karak, P.; Dastidar, S.G.; Motohashi, N.; Shirataki, Y. (2007). Studies on the antimicrobial potential of the cardiovascular drug lacidipine. In Vivo. 21, $847-850$

6. Dash, S.K.; Dastidar, S.G.; Chakrabarty, A.N. (1977). Antimicrobial activity of promazine hydrochloride. Indian J. Exp. Biol. 15, 324-326.

7. Dastidar, S.G.; Chaudhuri, A.; Annadurai, S.; Ray, S.; Mookherjee, M.; Chakrabarty, A.N. (1995). In vitro and in vivo antimicrobial action of fluphenazine. J. Chemother. 7, 201-206.

8. Dastidar, S.G.; Das, S.; Mookerjee, M.; Chattopadhyay, D.; Ray, S; Chakrabarty, A.N. (1988). Antibacterial activity of local anaesthetics procaine and lignocaine. Indian J. Med. Res. 87, 506-508. 
9. Dastidar, S.G.; Ganguly, K.; Chaudhury, K.; Chakrabarty, A.N. (2000). The anti-bacterial action of diclofenac shown by inhibition of DNA synthesis. Int. J. Antimicrob. Agents. 14, 249-251.

10. Dastidar, S.G.; Jairaj, J.; Mookerjee, M.; Chakrabarty, A.N. (1997). Studies on antimicrobial effect of the antihistaminic phenothiazine trimeprazine tartarate. Acta Microbiol. Immun. Hung. 44, 241-247.

11. Dastidar, S.G.; Mondal, U.; Niyogi, S.; Chakrabaty, A.N. (1986). Antibacterial property of methyl-DOPA and development of crossresistance in m-DOPA mutants. Indian J. Med. Res. 84, 142-147.

12. Dastidar, S.G.; Saha, P.K.; Sanyamat, B.; Chakrabarty, A.N. (1976). Antibacterial activities of Ambodryl and Benadryl. J. Appl. Bacteriol. 41, 209-214.

13. Karak, P.; Kumar, K.A.; Mazumdar, K.; Mookerjee, M.; Dastidar, S.G. (2003). Antibacterial potential of an antispasmodic drug dicyclomine hydrochloride. Indian J. Med. Res. 118, 192-196.

14. Kristiansen, J.E; Blom, J. (1981). Effect of Chlorpromazine on the ultra structure of Staphylococcus aureus. Acta Path. Microbiol. Scand. Sec B. $89,399-405$

15. Manna, K.K.; Dastidar, S.G. (1984) .The anti-hypertensive drug propranolol hydrochloride (carditap): its anti-bacterial property. In: Proceedings of the 6th National Congress of the Indian Association of Medical Microbiologists (IAMM).137-141.

16. Mazumdar, R.; Ganguly, K.; Dastidar, S.G.; Chakrabarty, A.N. (2001). Trifluoperazine: A broad-spectrum bactericide specially active on staphylococci and vibrios. Int. J. Antimicrob. Agents. 18, 403-406.

17. McFarland J. Nephelometer: an instrument for estimating the number of bacteria in suspensions used for calculating the opsonic index and for vaccines. J. Am. Med. Assoc. (1907). 49, 176-178.

18. Merck Index, Fourteenth Edition, p. 485.

19. Molnar, J.; Mandi, Y.; Kiraly, J. (1976). Antibacterial effect of some phenothiazine compounds and the R-factor elimination by chlorpromazine. Acta Microbiol. Acad. Sci. Hung. 23, 45-54.

20. National Committee for Clinical Laboratory Standards (2003). Methods for dilution antimicrobial susceptibility tests for bacteria that grow aerobically. Approved standard, 6th ed. NCCLS document M7-A6. NCCLS, Wayne, Pa.

21. Pal, T.; Dutta, N.K.; Mazumder, K.; Dasgupta, A.; Jeyaseeli, L.; Dastidar, S.G. (2006). Assesement of antibacterial activity of the cardiovascular drug Nifedipine. Oriental Pharmacy and Experimental Medicine. 6(2), 126-133.

22. Roy, K.; Chakrabarty, A.N. (1994). Anti-bacterial activities of antihistamine triprolidine hydrochloride (actidil) and cross-resistances to antibiotics developed by experimentally derived mutants resistant to this drug. Indian J. Med. Microbiol. 12, 9-18.

23. Saha, P.K.; Dastidar, S.G. (1976). Antimicrobial activity of antihistaminic drugs. Indian J. Med. Res. 64, 1677-1679.

24. Sarkar, A.; Kumar, K. A.; Dutta, N.K.; Chakraborty, P.; Dastidar, S.G. (2003). Evaluation of in vitro and in vivo antibacterial activity of dobutamine hydrochloride. Indian J. Med. Microbiol. 21(3), 172-178.

25. Uchida, K.; Yokota, N.; Yamaguchi, H. (2001). In vitro antifungal activity of posaconazole against various pathogenic fungi. Int. J. Antimicrob. Agents. 18(2), 167-172. 